\title{
Anastomotic leaks after anterior resection for mid and low rectal cancer: survey of the Italian Society of Colorectal Surgery
}

\author{
C.R. Asteria • G. Gagliardi • S. Pucciarelli • G. Romano • A. Infantino • F. La Torre • F. Tonelli • F. Martin • \\ C. Pulica • V. Ripetti • G. Diana • G. Amicucci • M. Carlini • A. Sommariva • G. Vinciguerra • D.B. Poddie • \\ A. Amato • R. Bassi • R. Galleano • E. Veronese • S. Mancini • G. Pescio • G.L. Occelli • S. Bracchitta • \\ M. Castagnola $\bullet$ T. Pontillo $\bullet$ G. Cimmino $\bullet$ U. Prati $\bullet$ R. Vincenti
}

Received: 14 January 2008 / Accepted: 10 April 2008 / Published online: 9 June 2008 (c) Springer-Verlag 2008

\begin{abstract}
Background The aim of the survey was to assess the incidence of anastomotic leaks (AL) and to identify risk factors predicting incidence and gravity of AL after low anterior resection (LAR) for rectal cancer performed by colorectal surgeons of the Italian Society of Colorectal Surgery (SICCR). Methods Information about patients with rectal cancers less than $12 \mathrm{~cm}$ from the anal verge who underwent LAR during 2005 was collected retrospectively. AL was classified as grade I to IV according to gravity. Fifteen clinical variables were examined by
\end{abstract}

This article was presented as a poster at the Second ESCP Meeting, Malta, 26-28 September 2007. univariate and multivariate analyses. Further analysis was conducted on patients with AL to identify factors correlated with gravity. Results There were 520 patients representing $64 \%$ of LAR for rectal cancer performed by SICCR members. The overall rate of AL was $15.2 \%$. Mortality was $2.7 \%$ including $0.6 \%$ from AL. The incidence of AL was correlated with higher age $(p<0.05)$, lower $(<20$ per year) centre case volume $(p<0.05)$, obesity $(p<0.05)$, malnutrition $(p<0.01)$ and intraoperative contamination $(p<0.05)$, and was lower in patients with a colonic J-pouch reservoir $(p<0.05)$. In the multivariate analysis age, malnutrition and intraoperative contamination were independent predictors. The only predictor of severe (grade III/IV) AL was alcohol/smoking habits $(p<0.05)$ while the absence of a diverting stoma was borderline significant $(p<0.07)$. Conclusions Our retrospective survey identified several risk factors for AL. This survey was a necessary step to construct prospective interventional studies and to establish benchmark standards for outcome studies.

Keywords Anastomotic leaks · Low anterior resection . Rectal cancer · Outcome studies

\section{Introduction}

Anastomotic leakage (AL) is the most significant surgical complication following resection for rectal cancer [1], affecting perioperative mortality and possibly longterm survival $[2,3]$. The rate of AL after anterior resection (AR) varies from 3\% to $19 \%$ [4-11], being clinically significant in 2.9-15.3\% of patients. Mortality following a leak may be 6.0-39.3\% [12]. Most of the reports of complications after surgery for colorectal cancer come
Department of Clinical Physiopathology

AOU Careggi, University of Florence

Via Morgagni 85, I-50134 Florence, Italy

Tel.: +39-0376-326051

Fax: +39-0376-721250

E-mail: corrado.asteria@libero.it

*Please see further affiliations at the end of the article 
from single institutions [1, 13-23] or are populationbased outcome studies [24-30]. Only a minority of studies are nationwide multi-institutional surveys [31-33]. Comparison of complication rates between series is difficult because of the different referral patterns and different study periods, and because relatively few studies distinguish between colon and rectal site, since the incidence of AL is higher after rectal cancer surgery $[5,25]$.

The aim of this study was to assess the incidence and gravity of AL after surgery for rectal cancer performed by Italian colorectal surgeons, and to identify factors predicting the incidence and gravity of AL in this patient population.

\section{Patients and methods}

Study population

The study was retrospective multicentre survey, including all patients with a new diagnosis of mid or low rectal cancer who underwent sphincter saving surgery, excluding local excisions, between 1 January and 31 December 2005. All surgical centres affiliated with the Italian Society of Colorectal Surgery were contacted by e-mail and invited to participate on a voluntary basis. An online database was created and devised to maintain patient anonymity. Because of the retrospective nature of the survey approval by an ethics committee was not required.

Data included patient-related variables (sex, age, BMI greater then $30 \mathrm{~kg} / \mathrm{m}^{2}$, weight loss greater than $10 \%$ within 6 months, and smoking and alcohol habits), disease-related variables (stage IV) and treatment-related variables (centre case volume, type of resection, open vs. laparoscopic

approach, intraoperative contamination, anastomotic level, type of anastomosis, stoma construction, blood transfusions, and adjuvant therapy). The minimum follow-up period required was 30 days after AR or after stoma closure in those patients with a temporary stoma.

To assess the gravity of AL the classification described by Soeters et al. [34] was used which includes four progressive severity grades (Table 1). When assess-

Table 1 Classification of anastomotic leaks (according SoetersBaeten)

\begin{tabular}{ll} 
Grade & Type of leak \\
\hline 1 & $\begin{array}{l}\text { Limited leakage with small adjacent abscess; } \\
\text { mild clinical signs }\end{array}$ \\
2 & $\begin{array}{l}\text { Small lateral anastomotic failure with adjacent unilocular } \\
\text { abscess (approximately } 5 \text { cm diameter or greater) }\end{array}$ \\
3 & $\begin{array}{l}\text { Failure of half or more of the circumference of } \\
\text { an anastomosis }\end{array}$ \\
Multilocular abscess or peritonitis
\end{tabular}

ing factors predicting the gravity of $\mathrm{AL}$ among patients with AL this classification was simplified to mild to moderate (grades 1 and 2) and severe (grades 3 and 4).

Categorical variables were evaluated using either Fisher's exact test or Pearson's chi-squared test depending on sample size. Numerical variables were evaluated using Student's $t$-test. $P$ values $<0.05$ were considered significant. All variables which were associated with the incidence or gravity of AL in the univariate analysis were entered into a multivariate logistic regression model. Data were analysed using the STATA program (release 8.0, 2003; Stata Corporation, College Station, TX).

\section{Results}

Of 108 centres contacted, 44 (40.7\%) participated. Information on 682 patients with rectal cancer who had undergone surgery was collected. Sphincter-saving surgery was performed in 579 patients (84.9\%). After excluding abdominoperineal resections $(n=100)$, local excisions $(n=37)$, Hartmann's procedure $(n=15)$ and other types of restorative $(n=7)$ and nonrestorative $(n=3)$ procedures, a group of 520 patients who had undergone a low AR (LAR) or coloanal anastomosis (CAA) were evaluated.

According to the Italian Network of Cancer Registries, the incidence of newly diagnosed rectal cancer in Italy in 2005 was approximately 15,000 cases [35]. According to the Society's 2005 annual report, SICCR members operated on 1,185 mid-low rectal cancers, and $815(68.8 \%)$ of them were treated with sphincter-saving procedures [36]. Our patient sample including only anastomotic surgery represents $63.8 \%$ (520/815) of all those with mid-low rectal cancers who underwent sphinctersaving surgery performed by SICCR members.

The mean age of the patients was 65.366 years (SD 9.688 years) and 287 of the 520 patients $(55.2 \%)$ were male. The number of procedures per centre ranged from 3 to 37 per year. The case volume distribution is shown in Fig. 1.

Among the surgical procedures 500 (96.15\%) were LARs and $20(3.85 \%)$ were CAAs. Of the 520 procedures, 87 (17.4\%) were performed laparoscopically. Anastomoses were stapled in 459 procedures $(91.8 \%)$ and hand-sewn in 61 procedures $(8.2 \%)$ including 18 of the 20 CAAs (90\%). Anastomoses were performed using a Jpouch in 54 of the 520 procedures $(10.4 \%)$, and with a transverse coloplasty in $8(1.5 \%)$. A diverting stoma was used in 294 procedures $(56.5 \%)$ including all the CAAs.

Postoperative adjuvant radiotherapy was used in 71 of the 520 patients $(13.6 \%)$ and was combined with chemotherapy in 64. Neoadjuvant radiotherapy was used 


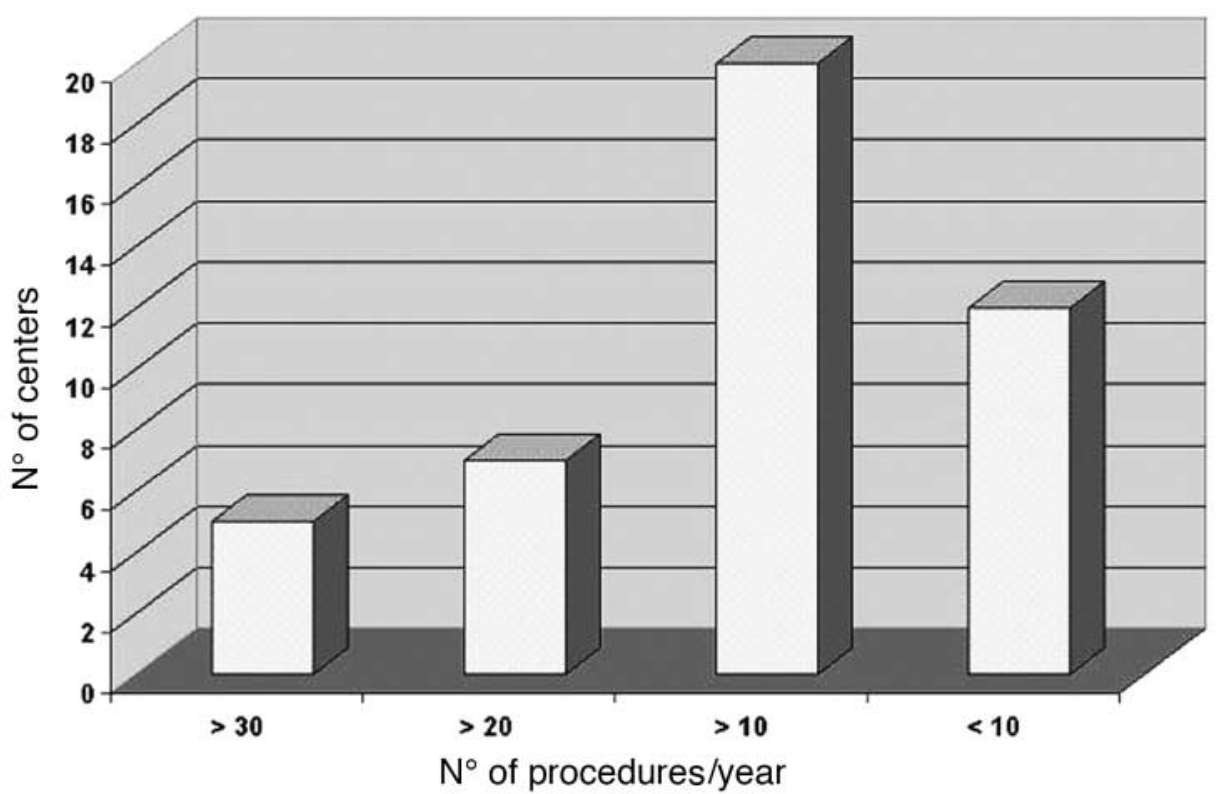

Fig. 1 Case volume distribution

in 187 patients (39.6\%), and of these 187, $18(9.6 \%)$ were done using a short-term protocol $(2,000 \mathrm{rad}$ over 5 days followed by immediate surgery, and 169 (90.4\%) were done using a long-term protocol (4,000-4,500 rad over 5 weeks followed by a waiting period of 6-8 weeks) combined with chemotherapy in 164 .

The overall incidence of AL was $15.2 \%$ (79 of 520), and $12(2.3 \%)$ patients died within 30 days of surgery including 3 patients $(0.58 \%)$ with AL. Of the 79 patients with AL, $32(40.5 \%)$ were grade 1, 26 (32.9\%) were grade $2,17(21.5 \%)$ were grade 3 , and $4(5.1 \%)$ were grade 4 . Of the 520 patients, $22(4.2 \%)$ underwent a routine radiographic contrast study prior to discharge from hospital and 6 of these had a small asymptomatic grade 1 leak, comprising $7.9 \%$ of all ALs.

The mean hospital stay was 12.04 days (SD 6.29). Among the 79 patients with AL, the mean hospital stay was of 14.57 days (SD 5.14) which was significantly higher than the hospital stay of patients without AL $(9.433 \pm 7.440$ days; $p<0.003)$.

In the univariate analysis (Table 2) the occurrence of AL was correlated with higher age $(68.60 \pm 11.86$ years vs. $62.13 \pm 7.51$ years; $p<0.014)$, lower $(<20$ per year) centre case volume (OR 1.88, 95\% CI 1.15-3.07; $p=0.011$ ), obesity (OR 2.03, 95\% CI 1.03-4.00; $p=0.038$ ), malnourished state (OR 2.80, 95\% CI 1.52-5.18; $p<0.001)$ and intraoperative contamination (OR 3.47, 95\% CI 1.32-9.12; $p=0.016$ ). The incidence $\mathrm{AL}$ was lower in patients with a colonic J-pouch reservoir (OR 0.283, 95\% CI 0.086-0.928; $p=0.027$ ). In the multivariate analysis (Table 3 ) the independent predictive factors were higher age (OR 1.025, 95\% CI 0.999-1.051; $p=0.057$ ), intraoperative contamination (OR 1.33, 95\% CI 1.01-1.761; $p=0.041)$ and malnourished state (OR
$1.621741,95 \%$ CI $1.238-2.122 ; p=0.001)$. Among the 79 patients with AL a univariate analysis was conducted to find predictors of AL gravity. Severe (grade 3 and 4) AL was correlated with alcohol and/or smoking habits (OR 13.651, 95\% CI 0.775-240.43; $p=0.05$ ) while absence of a diverting stoma was only borderline significant (OR $0.326,95 \%$ CI $0.106-1 ; p=0.07)$.

\section{Discussion}

To our knowledge this is the first Italian nationwide study on the incidence of AL among colorectal surgeons. Since the cases collected represent $64 \%$ of all rectal cancers operated on with a sphincter-saving procedure by the members of our Society in 2005 we consider the sample representative. Our AL incidence of $15.9 \%$ seems quite high compared to other studies in which it has been found to range from $2.9 \%$ to $14 \%[17,28,31,37]$. In our sample of 682 patients with rectal cancer undergoing surgery, sphincter-saving procedures were carried out in $85 \%$ of patients, which is a very high percentage. The increased AL rate may be related to the number of highrisk low rectal anastomoses [38]. Conversely our in-hospital mortality of $2.3 \%$ is in the lower range compared to a multicentre studies from Germany $(2.7-3.1 \%)$ [31, 39], Sweden (1-4\% ) [28], Norway (3.0\%) [33] and United Kingdom (7\%) [25].

We found that hospital case volume correlated with a lower incidence of AL. Others have found that higher surgeon case volume is associated with lower rates of morbidity regardless of the hospital case volume [28, 32, 40]. Nevertheless, hospital case volume has been found to be a good surrogate for surgeon case volume [41]. Our 


\begin{tabular}{|c|c|c|c|c|c|c|}
\hline Variable & $\begin{array}{l}\text { Patients } \\
\text { with AL }\end{array}$ & $\begin{array}{l}\text { Patients } \\
\text { without AL }\end{array}$ & Odds ratio & $95 \% \mathrm{CI}$ & $\begin{array}{l}\text { Chi squared } \\
\text { or Student's } t\end{array}$ & $p$ value \\
\hline Median age (years) & $68.60(\mathrm{SD} 11.86)$ & $62.13(\mathrm{SD} 7.51)$ & & & 2.521 & $<0.014 *$ \\
\hline \multicolumn{7}{|l|}{ Gender } \\
\hline Male & $44(15.3 \%)$ & $243(84.7 \%)$ & 1.024 & $0.633-1.659$ & 0.009 & 0.922 \\
\hline Female & $35(15 \%)$ & $198(85 \%)$ & & & & \\
\hline \multicolumn{7}{|l|}{ Obesity } \\
\hline Obese & $13(25 \%)$ & $39(75 \%)$ & 2.030 & $1.029-4.006$ & 4.313 & $<0.038^{*}$ \\
\hline Non-obese & $66(14.1 \%)$ & $402(85.9 \%)$ & & & & \\
\hline \multicolumn{7}{|l|}{ Nutritional status } \\
\hline Malnourished & $18(30 \%)$ & $42(70 \%)$ & 2.803 & $1.516-5.182$ & 11.542 & $0.001 *$ \\
\hline Not malnourished & $61(13.3 \%)$ & $399(86.7 \%)$ & & & & \\
\hline \multicolumn{7}{|l|}{ Blood transfusion } \\
\hline Yes & $7(11.9 \%)$ & $25(78.1 \%)$ & 1.617 & $0.674-3.879$ & 1.181 & 0.277 \\
\hline No & $72(14.8 \%)$ & $416(85.2 \%)$ & & & & \\
\hline \multicolumn{7}{|l|}{ Neoadjuvant therapy } \\
\hline Yes & $25(13.4 \%)$ & $162(86.6 \%)$ & 0.703 & $0.422-1.173$ & 1.828 & 0.176 \\
\hline No & $54(16.2 \%)$ & $279(83.8 \%)$ & & & & \\
\hline \multicolumn{7}{|l|}{ Stage } \\
\hline IV & $13(15 \%)$ & $74(85 \%)$ & 0.976 & $0.512-1.862$ & 0.005 & 0.943 \\
\hline I-III & $66(15.3 \%)$ & $367(84.7 \%)$ & & & & \\
\hline \multicolumn{7}{|l|}{ Smoking or alcohol habits } \\
\hline Yes & $13(16.7 \%)$ & $65(83.3 \%)$ & 1.139 & $0.594-2.183$ & 0.154 & 0.694 \\
\hline No & $66(14.9 \%)$ & $376(85.1 \%)$ & & & & \\
\hline \multicolumn{7}{|l|}{ Centre case volume (no. per year) } \\
\hline$<20$ & $49(19.3 \%)$ & $205(80.7 \%)$ & 1.880 & $1.150-3.073$ & 6.475 & $0.011 *$ \\
\hline$\geq 20$ & $30(11.3 \%)$ & $236(88.7 \%)$ & & & & \\
\hline \multicolumn{7}{|l|}{ Procedure } \\
\hline Open & $63(14.9 \%)$ & $359(85.1 \%)$ & 0.899 & $0.494-1.636$ & 0.120 & 0.728 \\
\hline Laparoscopic & $16(16.3 \%)$ & $82(83.7 \%)$ & & & & \\
\hline \multicolumn{7}{|l|}{ Distance of anastomosis } \\
\hline \multicolumn{7}{|l|}{ from anal verge $(\mathrm{cm})$} \\
\hline$<5$ & $36(15.7 \%)$ & $194(84.3 \%)$ & 1.065 & $0.658-1.724$ & 0.067 & 0.795 \\
\hline$>5$ & $43(14.8 \%)$ & $247(85.2 \%)$ & & & & \\
\hline \multicolumn{7}{|l|}{ Technique } \\
\hline Hand-sewn anastomosis & $9(12.9 \%)$ & $61(87.1 \%)$ & 0.800 & $0.380-1.686$ & 0.342 & 0.558 \\
\hline Stapled anastomosis & $70(15.6 \%)$ & $380(84.4 \%)$ & & & & \\
\hline $\mathrm{J}$-pouch anastomosis & $3(5.3 \%)$ & $54(94.7 \%)$ & 0.282 & $0.086-0.928$ & 4.898 & $0.027 *$ \\
\hline Straight anastomosis or coloplasty & $76(16.2 \%)$ & $387(83.6 \%)$ & & & & \\
\hline \multicolumn{7}{|c|}{ Intraoperative contamination } \\
\hline Yes & $7(36.9 \%)$ & $12(63.1 \%)$ & 3.475 & $1.324-9.123$ & $\S$ & $0.016 *$ \\
\hline No & $72(14.4 \%)$ & $429(85.6 \%)$ & & & & \\
\hline \multicolumn{7}{|l|}{ Diverting stoma } \\
\hline No & $47(16.1 \%)$ & $245(83.9 \%)$ & 1.175 & $0.722-1.912$ & 0.422 & 0.516 \\
\hline Yes & $32(14 \%)$ & $196(86 \%)$ & & & & \\
\hline
\end{tabular}

$* p<0.05 ; \S$ Fisher's exact test

study shows a very heterogeneous case volume distribution (Fig. 1) as is often the case for multicentre surveys. A lower incidence of ALs after J-pouch anastomosis has been previously shown $[33,42]$ and is confirmed by our study. Nevertheless, none of the randomized trials of $\mathrm{J}$ pouch vs. straight anastomosis were adequately powered to detect a difference in ALs. A J-pouch or coloplasty was fashioned only in $11 \%$ of procedures. This despite the body of literature outlining short-term functional advantages of the J-pouch or coloplasty [43]. Our observation that malnutrition is correlated with $\mathrm{AL}$ confirms what others have found $[32,44]$ and emphasizes the need for careful preoperative assessment and the importance of pre- and postoperative diet. Also intraoperative contamination has been consistently found to be associated with $\mathrm{AL}[1,10,33,45]$. In the multivariate analysis higher age, malnourished state and intraoperative contamination were correlated with AL. These results are similar to those of other studies [10, 33, 46-48].

In our survey smoking/alcohol habits, while they were not correlated with incidence of AL as in other studies [47], were frequently associated with more severe leaks in the subset of patients with AL. Alcohol abusers (more than 35 drinks per week) have a significantly higher risk 
Table 3 Results of the univariate analysis of the gravity of AL (grade 3 and 4) in the overall population with AL

\begin{tabular}{|c|c|c|c|c|c|c|}
\hline Variable & AL grade $1-2$ & AL grade $3-4$ & Odds ratio & $95 \% \mathrm{CI}$ & $\begin{array}{l}\text { Chi squared } \\
\text { or Student's } t\end{array}$ & $p$ value \\
\hline Median age (years) & $68.69(\mathrm{SD} 10.83)$ & $68.42(\mathrm{SD} 9.25)$ & & & 0.104 & 0.458 \\
\hline \multicolumn{7}{|l|}{ Gender } \\
\hline Male & $29(67.4 \%)$ & $14(32.6 \%)$ & 0.591 & $0.215-1.628$ & 1.041 & 0.307 \\
\hline Female & $28(77.8 \%)$ & $8(12.2 \%)$ & & & & \\
\hline \multicolumn{7}{|l|}{ Obesity } \\
\hline Obese & $8(61.5 \%)$ & $5(38.5 \%)$ & 0.555 & $0.159-1.930$ & $\S$ & 0.269 \\
\hline Non-obese & $49(74.2 \%)$ & $17(25.8 \%)$ & & & & \\
\hline \multicolumn{7}{|l|}{ Nutritional status } \\
\hline Malnourished & $15(83.3 \%)$ & $3(16.7 \%)$ & 2.261 & $0.584-8.750$ & 1.450 & 0.228 \\
\hline Not malnourished & $42(68.9 \%)$ & $19(31.1 \%)$ & & & & \\
\hline \multicolumn{7}{|l|}{ Blood transfusion } \\
\hline Yes & $3(42.9 \%)$ & $4(57.1 \%)$ & 0.264 & $0.55-1.175$ & $\S$ & 0.090 \\
\hline No & $54(75.0 \%)$ & $18(25.0 \%)$ & & & & \\
\hline \multicolumn{7}{|l|}{ Neoadjuvant therapy } \\
\hline Yes & $19(73.1 \%)$ & $7(26.9 \%)$ & 1.046 & $0.374-2.926$ & 0.016 & 0.898 \\
\hline No & $38(71.7 \%)$ & $15(28.3 \%)$ & & & & \\
\hline \multicolumn{7}{|l|}{ Stage } \\
\hline IV & $8(61.5 \%)$ & $5(38.5 \%)$ & 0.546 & $0.164-1.819$ & $\S$ & 0.269 \\
\hline I-III & $49(74.2 \%)$ & $17(25.8 \%)$ & & & & \\
\hline \multicolumn{7}{|l|}{ Smoking or alcohol habits } \\
\hline Yes & $13(100 \%)$ & $0(0 \%)$ & $13.651 \dagger$ & $0.77-24.043$ & $\S$ & $0.015^{*}$ \\
\hline No & $44(66.7 \%)$ & $22(33.3 \%)$ & & & & \\
\hline \multicolumn{7}{|l|}{ Centre case volume (no. per year) } \\
\hline$<20$ & $35(71.4 \%)$ & $14(28.6 \%)$ & 0.924 & $0.341-2.508$ & 0.033 & 0.855 \\
\hline$>20$ & $22(73.3 \%)$ & $8(26.7 \%)$ & & & & \\
\hline \multicolumn{7}{|l|}{ Procedure } \\
\hline Open & $44(69.8 \%)$ & $19(30.2 \%)$ & 0.534 & $0.136-2.094$ & $\S$ & 0.535 \\
\hline Laparoscopic & $13(81.3 \%)$ & $3(18.7 \%)$ & & & & \\
\hline \multicolumn{7}{|l|}{ Distance of anastomosis } \\
\hline $\begin{array}{l}\text { from anal verge }(\mathrm{cm}) \\
<5\end{array}$ & & $9(11.4 \%)$ & 2135 & $0784-5811$ & 2.247 & 0134 \\
\hline $\begin{array}{l}<5 \\
>5\end{array}$ & $\begin{array}{l}34(68.6 \%) \\
23(63.9 \%)\end{array}$ & $\begin{array}{l}9(11.4 \%) \\
13(16.1 \%)\end{array}$ & 2.135 & $0.184-5.811$ & 2.247 & 0.134 \\
\hline \multicolumn{7}{|l|}{ Technique } \\
\hline Hand-sewn anastomosis & $7(77.8 \%)$ & $2(12.2 \%)$ & 1.4 & $0.267-7.325$ & $\S$ & 0.517 \\
\hline Stapled anastomosis & $50(71.4 \%)$ & $20(28.6 \%)$ & & & & \\
\hline $\mathrm{J}$-pouch anastomosis & $3(100 \%)$ & $0(0.0 \%)$ & 2.889 & $0.143-5.825$ & $\S$ & 0.556 \\
\hline Straight anastomosis or coloplasty & $54(71.1 \%)$ & $22(28.9 \%)$ & & & & \\
\hline \multicolumn{7}{|l|}{ Intraoperative contamination } \\
\hline Yes & $3(42.8 \%)$ & $4(57.2 \%)$ & 0.25 & $0.051-1.224$ & $\S$ & 0.090 \\
\hline No & $54(75.0 \%)$ & $18(25.0 \%)$ & & & & \\
\hline \multicolumn{7}{|l|}{ Diverting stoma } \\
\hline No & $30(63.8 \%)$ & $17(36.2 \%)$ & 0.326 & $0.106-1$ & $\S$ & 0.072 \\
\hline Yes & $27(84.4 \%)$ & $5(15.6 \%)$ & & & & \\
\hline
\end{tabular}

$*_{p<0.05 ;} \S$ Fisher's exact test; $\dagger$ Calculated using the approximation of Woolf

of developing AL than abstainers [49], and the causes are probably immunosuppression and decreased haemostatic function [50]. Moreover, it has been suggested that the effect of smoking in reducing collagen synthesis and oxidative killing mechanisms of neutrophils explains higher rates of AL [51]. Construction of a diverting stoma was weakly correlated with a lower AL rate. The benefit of a diverting stoma following LAR has not been unequivocally demonstrated [31]. Indeed, the use of a diverting stoma seems not to decrease the leakage rate $[38,52]$, but it does reduce the risk of reoperation and postoperative death if leakage is present [1]. Therefore, the guidelines of the American Society of Colon and Rectal Surgeons [53] recommend creating a protective stoma for patients who show a combination of high-risk variables for AL. Finally, hospital stay was significantly longer in patients with AL. This highlights the weight of $\mathrm{AL}$ in terms of morbidity and of increased hospital costs.

Stapling of the anastomosis was the preferred technique being used in $92 \%$ of procedures. The percentage of CAAs was low (2.9\%) which may have been due to the known poor functional results and quality of life reported after this procedure $[53,54]$. A laparoscopic approach was used in $18 \%$ of patients which is similar to the per- 
centage of laparoscopic colorectal surgery procedures in other international studies $[55,56]$. Laparoscopic total mesorectal excision appears to have clinically measurable short-term advantages in patients with primary resectable rectal cancer [57], although long-term oncological results are awaited from large on-going randomized trials [42].

The incidence of AL has been determined in national and multicentre surveys [31-33]. A limitation of these studies is that they included heterogeneous types of procedures. The Norwegian national audit on complications following rectal cancer excision rapresents to our knowledge the only attempt to standardize the surgical procedure variable [23, 30, 58].

There is a recognized lack of a universally accepted definition of AL. Indeed, a systematic review reported 29 different definitions of AL among 49 studies [59]. This may have been due to factors such as subjective interpretation of clinical signs or to whether a water-soluble enema was routinely used. In our survey we adopted the classification proposed by Soeters et al. which allows discrimination between clinically relevant severe AL (grade III-IV) usually requiring surgical intervention and small leaks which may respond to conservative treatment.

The limitation of our study is in its retrospective nature since retrospective collection of risk factors may be subject to bias. The aim of the survey was to provide preliminary data on the incidence and gravity of ALs among Italian colorectal surgeons. The risk factors identified should now be prospectively studied. The protective effect of the colonic J-pouch on ALs should be investigated with adequately powered randomized trials. In order to establish a useful benchmark standard for outcome studies, a prospective study should be carried out to standardize surgical variables such as stoma construction including only high-volume centres.

Conflict of interest statement The authors declare that they have no conflict of interest related to the publication of this article.

Acknowledgements The authors are indebted to all 44 centres that participated voluntarily and accurately in reporting their data. We are also grateful to Prof. Francesco Donato MD (Health Department, School of Medicine, Brescia University, Italy) and to Dr. Chiara Minari (Medical Physics, "C. Poma" Hospital, Mantua, Italy) for statistical advice and calculations, and to Alexandra Grenga and Domenico Mangiacapra (Q-net Softerhouse, Codroipo, Italy) for help in organizing the survey.

\footnotetext{
*Authors' affiliations

G. Gagliardi

Department of Surgery, Clinica Pineta Grande, Castel Volturno, Italy

S. Pucciarelli

Department of Oncological and Surgical Sciences, 2nd Surgical Clinic, Padua University, Italy
}

G. Romano

Department of Surgery, Moscati Hospital, Avellino, Italy

A. Infantino

Department of Surgery, S. Maria dei Battuti Hospital, S. Vito al Tagliamento (PN), Italy

F. La Torre

Department of Surgery, Policlinico, University of Rome, Italy

F. Martin

2nd Department of Surgery, Regional Hospital, Bolzano, Italy

C. Pulica

Department of Surgery, C. Poma Hospital, Mantua, Italy

V. Ripetti

Department of Surgery, Campus Bio-Medico,

University of Rome, Italy

G. Diana

Department of Surgery, Policlinico, University of Palermo, Italy

G. Amicucci

Department of Surgery, Policlinico, University of L'Aquila, Italy

M. Carlini

Department of Surgery, S. Eugenio Hospital, Rome, Italy

A. Sommariva

Department of Surgery, S.S. Giovanni Paolo Hospital, Venice, Italy

G. Vinciguerra

Department of Surgery, Civic Hospital, Carrara, Italy

D.B. Poddie

Department of Surgery, AUSL Hospital, Ravenna, Italy

A. Amato

Department of Surgery,

Coloproctology Unit Civic Hospital, Sanremo (IM), Italy

R. Bassi

Department of Surgery, Maggiore Hospital, Crema (CR), Italy

R. Galleano

Department of Surgery, Civic Hospital, Albenga (SV), Italy

E. Veronese

Department of Surgery, Civic Hospital, San Bonifacio (VR), Italy

S. Mancini

Department of Surgery, Civic Hospital,

Civitanova Marche (MC), Italy

G. Pescio

Department of Surgery, Civic Hospital, Imperia, Italy

G.L. Occelli

Department of Surgery, Civic Hospital, Suzzara (MN), Italy

S. Bracchitta

Department of Surgery, Clinica del Mediterraneo, Ragusa, Italy

M. Castagnola

Department of Surgery, ASL 3 Nord Hospital, Genoa, Italy

T. Pontillo

Department of Surgery, Cannizzaro Hospital, Catania, Italy

G. Cimmino

Department of Surgery,

San Giovanni di Dio Hospital, Frattaminore (NA), Italy 
U. Prati

Department of Surgery,

Madonna delle Grazie Hospital, Matera, Italy

R. Vincenti

Department of Surgery, Buon Consiglio Hospital, Naples, Italy

\section{References}

1. Rullier E, Laurent C, Garrelon JL et al (1998) Risk factors for anastomotic leakage after resection of rectal cancer. Br J Surg 85:355-358

2. Petersen S, Freitag M, Hellmich G et al (1998) Anastomotic leakage: impact on local recurrence and survival in surgery of colorectal cancer. Int J Colorectal Dis 13:160-163

3. Fujita S, Teramoto T, Watanabe M et al (1993) Anastomotic leakage after colorectal cancer surgery: a risk factor for recurrence and poor prognosis. Jpn J Clin Oncol 23:299-302

4. Fielding LP, Stewart-Brown S, Blesovsky L, Kearney G (1980) Anastomotic integrity after operations for large-bowel cancer: a multicentre study. Br Med J 281:411-414

5. Heald RJ (1981) The low stapled anastomosis. Br J Surg 68:333-337

6. Antonsen HK, Kronborg O (1987) Early complications after low anterior resection for rectal cancer using the EEA stapling device. A prospective trial. Dis Colon Rectum 30:579-583

7. Karanja ND, Corder AP, Bearn P Heald RJ (1994) Leakage from stapled low anastomosis after total mesorectal excision for carcinoma of the rectum. Br J Surg 81:1224-1246

8. Mann B, Kleinschmidt S, Stremmel W (1996) Prospective study of hand-sutured anastomosis after colorectal resection. Br J Surg $83: 29-31$

9. Alberts JC, Parvaiz A, Moran BJ (2003) Predicting risk and diminishing the consequences of anastomotic dehiscence following rectal resection. Colorectal Dis 5:478-482

10. Matthiessen P, Hallbook O, Andersson M et al (2004) Risk factors for anastomotic leakage after anterior resection of the rectum. Colorectal Dis 6:462-469

11. Law WL, Chu KW (2004) Anterior resection for rectal cancer with mesorectal excision: a prospective evaluation of 622 patients. Ann Surg 240:260-268

12. Chambers WM, Mortensen NJ (2004) Postoperative leakage and abscess formation after colorectal surgery. Best Pract Res Clin Gastroenterol 18:865-880

13. Lockhart-Mummery HE, Ritchie JK, Hawley PR (1976) The results of surgical treatment for carcinoma of the rectum at $\mathrm{St}$ Mark's Hospital from 1948 to 1972. Br J Surg 63:673-677

14. Beard CM, Spencer RJ, Weiland LH et al (1995) Trends in colorectal cancer over half a century in Rochester, Minnesota, 1940 to 1989. Ann Epidemiol 5:210-214

15. Bergamaschi R (1995) Surgical strategies in the treatment of colorectal cancer. Eur J Surg 161 [Suppl 575]:5-22

16. Bell JC (1997) Trends in colorectal cancer incidence and mortality in New South Wales, 1973-1992. Med J Aust 166:178-181

17. Vignali A, Fazio VW, Lavery IC et al (1997) Factors associated with the occurrence of leaks in stapled rectal anastomoses: a review of 1,014 patients. J Am Coll Surg 185:105-113

18. Blomqvist P, Ekbom A, Nyren O et al (1997) Survival after colon cancer 1973-1990 in Sweden. Convergence between catchment areas. Ann Surg 225:208-216

19. Holm T, Johansson H, Cedermark B et al (1997) Influence of hospital- and surgeon-related factors on outcome after treatment for rectal cancer with and without preoperative radiotherapy. $\mathrm{Br} \mathrm{J}$ Surg 84:657-663

20. Koyama Y, Kotake K (1997) Overview of colorectal cancer in Japan: report from the Registry of the Japanese Society for
Cancer of the Colon and Rectum. Dis Colon Rectum 40 [10 Suppl]:S2-S9

21. Singh KK, Barry MK, Ralston P et al (1997) Audit of colorectal cancer surgery by non- specialist surgeons. Br J Surg 84:343-347

22. Moran B, Heald RJ (2000) Anastomotic leakage after colorectal anastomosis. Semin Surg Oncol 18:244-248

23. Nesbakken A, Nygaard K, Westerheim O, Lunde OC, Mala T (2002) Audit of intraoperative and early postoperative complications after introduction of mesorectal excision for rectal cancer. Eur J Surg 168:229-235

24. Evans JT, Vana J, Aronoff BL et al (1985) Management and survival of colorectal carcinoma: results of a national survey by the American College of Surgeons. Ann Surg 188:716-720

25. Phillips RK, Hittinger R, Blesovsky L et al (1984) Local recurrence following 'curative' surgery for large bowel cancer: II. The rectum and rectosigmoid. Br J Surg 71:17-20

26. Platell C (1997) A community-based hospital experience with colorectal cancer. Aust N Z J Surg 67:420-423

27. Mella J, Biffin A, Radcliffe AG et al (1997) Population-based audit of colorectal cancer management in two UK health regions. Br J Surg 84:1731-1736

28. Martling AL, Holm T, Rutqvist LE et al (2000) Effect of a surgical training programme on outcome of rectal cancer in the County of Stockholm. Stockholm Colorectal Cancer Study Group, Basingstoke Bowel Cancer Research Project. Lancet 8356:93-96

29. Semmens JB, Platell C, Threlfall TJ et al (2000) A populationbased study of the incidence, mortality and outcomes in patients following surgery for colorectal cancer in Western Australia. Aust N Z J Surg 70:11-18

30. Wibe A, Møller B, Norstein J et al; Norwegian Rectal Cancer Group (2002) A national strategic change in treatment policy for rectal cancer - implementation of total mesorectal excision as routine treatment in Norway. A national audit. Dis Colon Rectum 45:857-866

31. Marush F, Koch A, Schmidt U et al (2002) Value of a protective stoma in low anterior resections for rectal cancer. Dis Colon Rectum 45:1164-1171

32. Alves A, Panis Y, Mathieu P et al; Association Française de Chirurgie (2005) Postoperative mortality and morbidity in French patients undergoing colorectal surgery: results of a prospective multicenter study. Arch Surg 140:278-283

33. Eriksen MT, Wibe A, Norstein J et al; Norwegian Rectal Cancer Group (2005) Anastomotic leakage following routine mesorectal excision for rectal cancer in a national cohort of patients. Colorectal Dis 7:51-57

34. Soeters PB, de Zoete JP, Dejong CH et al (2002) Colorectal surgery and anastomotic leakage. Dig Surg 19:150-155

35. Italian Network of Cancer Registries, on behalf of National Center for Disease (2008) Prevention and Control of the Public Health Ministry, Rome. http://www.tumori.net/it/banca_dati/query.php. Accessed 15 April 2008

36. Bruni T, Occelli G (2006) The Italian Society of Colorectal Surgery (SICCR) Annual Report of the Coloproctology Units (UCP Club). Tech Coloproctol 10:274-275

37. Kapiteijn E, Kranenbarg EK, Steup WH et al (1999) Total mesorectal excision (TME) with or without preoperative radiotherapy in the treatment of primary rectal cancer. Prospective randomised trial with standard operative and histopathological techniques. Dutch Colorectal Cancer Group. Eur J Surg 165:410-420

38. Karanjia ND, Corder AP, Holdsworth PJ, Heald RJ (1991) Risk of peritonitis and fatal septicaemia and the need to defunction the low anastomosis. Br J Surg 78:196-198

39. Kessler H, Hermanek P Jr, Wiebelt H (1993) Operative mortality in carcinoma of the rectum. Results of the German Multicentre Study. Int J Colorectal Dis 8:158-166

40. Prystowsky JB, Bordage G, Feinglass JM (2002) Patient outcomes for segmental colon resection according to surgeon's training, certification, and experience. Surgery 132:663-670 
41. Harmon JW, Tang DG, Gordon TA et al (1999) Hospital volume can serve as a surrogate for surgeon volume for achieving excellent outcomes in colorectal resection. Ann Surg 230:404-411

42. Murray A, Lourenco T, de Verteuil R et al (2006) Clinical effectiveness and cost- effectiveness of laparoscopic surgery for colorectal cancer: systematic reviews and economic evaluation. Health Technol Assess 10:1-141, iii-iv

43. Hällbook O, Pahlman L, Krog M et al (1996) Randomized comparison of straight and colonic $\mathrm{J}$ pouch anastomosis after low anterior resection. Ann Surg 224:58-65

44. Braga M, Gianotti L, Nespoli L et al (2002) Nutritional approach in malnourished surgical patients: a prospective randomized study. Arch Surg 137:174-180

45. Carlsen E, Schlichting E, Guldvog I et al (1998) Effect of the introduction of total mesorectal excision for the treatment of rectal cancer. Br J Surg 85:526-529

46. Konishi T, Watanabe T, Kishimoto J et al (2006) Risk factors for anastomotic leakage after surgery for colorectal cancer: results of prospective surveillance. J Am Coll Surg 202:439-444

47. Mäkelä JT, Kiviniemi H, Laitinen S (2003) Risk factors for anastomotic leakage after left-sided colorectal resection with rectal anastomosis. Dis Colon Rectum 46:653-660

48. Matos DDM, Atallah A, Castro A, Silva Lustosa SA (2001) Stapled versus handsewn methods for colorectal anastomosis surgery. Cochrane Database of Systematic Reviews, issue 3, article no. CD003144. DOI: 10.1002/14651858.CD003144

49. Sørensen LT, Jørgensen T, Kirkeby LT et al (1999) Smoking and alcohol abuse are major risk factors for anastomotic leakage in colorectal surgery. Br J Surg 86:927-931

50. Tonnesen H, Kehlet H (1999) Preoperative alcoholism and posto- perative morbidity. Br J Surg 86:869-874

51. Sørensen LT, Nielsen HB, Kharazmi A et al (2004) Effect of smoking and abstention on oxidative burst and reactivity of neutrophils and monocytes. Surgery 136:1047-1053

52. Schrock TR, Deveney CW, Dunphy JE (1973) Factor contributing to leakage of colonic anastomoses. Ann Surg 177:513-518

53. Tjandra JJ, Kilkenny JW, Buie WD et al; The Standards Practice Task Force; The American Society of Colon and Rectal Surgeons (2005) Practice parameters for the management of rectal cancer (revised). Dis Colon Rectum 48:411-423

54. Temple LK, Bacik J, Savatta SG et al (2005) The development of a validated instrument to evaluate bowel function after sphincterpreserving surgery for rectal cancer. Dis Colon Rectum 48:1353-1365

55. Duval H, Dumont F, Vibert E et al (2006) The Association Française de Chirurgie (AFC) Colorectal index: a reliable preoperative prognostic index in colorectal surgery. Ann Chir 131:34-38

56. Harinath G, Shah PR, Haray PN, Foster ME (2005) Laparoscopic colorectal surgery in Great Britain and Ireland - where are we now? Colorectal Dis 7:86-89

57. Breukink S, Pierie J, Wiggers T (2006) Laparoscopic versus open total mesorectal excision for rectal cancer. Cochrane Database of Systematic Reviews, issue 4, article no. CD005200. DOI: 10.1002/14651858.CD005200.pub2

58. Wibe A, Carlsen E, Dahl O et al; The Norwegian Rectal Cancer Group. (2006) Nationwide quality assurance of rectal cancer treatment. Colorectal Dis 8:224-29

59. Bruce J, Krukowski ZH, Al-Khairy G et al (2001) Systematic review of the definition and measurement of anastomotic leak after gastrointestinal surgery. Br J Surg 88:1157-1168 